\title{
Applied phenomenology: why it is safe to ignore the epoché
}

\author{
Dan Zahavi ${ }^{1,2}$ (D) \\ Published online: 9 April 2019 \\ (C) The Author(s) 2019
}

\begin{abstract}
The question of whether a proper phenomenological investigation and analysis requires one to perform the epoché and the reduction has not only been discussed within phenomenological philosophy. It is also very much a question that has been hotly debated within qualitative research. Amedeo Giorgi, in particular, has insisted that no scientific research can claim phenomenological status unless it is supported by some use of the epoché and reduction. Giorgi partially bases this claim on ideas found in Husserl's writings on phenomenological psychology. In the present paper, I discuss Husserl's ideas and argue that while the epoché and the reduction are crucial for transcendental phenomenology, it is much more questionable whether they are also relevant for a non-philosophical application of phenomenology.
\end{abstract}

Keywords Phenomenology · Qualitative research · Phenomenological psychology · Applied phenomenology · Epoché · Reduction · Husserl · Giorgi

At its core, phenomenology is a philosophical endeavor. Its task is not to contribute to or augment the scope of our empirical knowledge, but rather to step back and investigate the nature and basis of this knowledge. Given the distinctly philosophical nature of this venture, one might reasonably wonder whether phenomenology can offer anything of value to positive science. Can it at all inform empirical work? There can, however, be no doubt about the answer to these questions. For more than a century, phenomenology has provided crucial inputs to a variety of disciplines in the social sciences and the humanities, including psychology, sociology, and anthropology. Within the last few decades, phenomenology has also been an important source of inspiration, not only for theoretical debates within qualitative research but also for ongoing research within the cognitive sciences.

Dan Zahavi

dan.zahavi@philosophy.ox.ac.uk

1 Faculty of Philosophy, University of Oxford, Radcliffe Humanities, Radcliffe Observatory Quarter, Woodstock Road, Oxford OX2 6GG, UK

2 Center for Subjectivity Research, University of Copenhagen, Copenhagen, Denmark 
This fact raises important questions about the relationship between philosophical phenomenology and applied phenomenology; questions that revive classical disagreements about the very nature of phenomenological research.

According to a widespread view, phenomenology should ultimately not be defined in terms of its subject matter, but rather in terms of its distinct method. But it has always been a matter of controversy how this method is to be further characterized. Husserl is well known for having argued that the epoché and the transcendental reduction are essential to phenomenology, and he has insisted that those who consider both to be irrelevant might use the term 'phenomenology', but will lack a proper understanding of what it actually amounts to. As is also well known, however, this is hardly a majority view among phenomenologists. It is indisputable that neither Heidegger nor Merleau-Ponty made many references to the epoché and the reduction, although it is contested whether this is so because they rejected Husserl's methodology, or because they simply took it for granted (cf. Zahavi 2017, 66-67, 172). But already much earlier, one can find phenomenologists who were unequivocal in their rejection of Husserl's transcendental turn. Husserl's early realist followers primarily saw the phenomenological return to 'the things themselves' as a turn away from (the Kantian focus on) subjectivity. For them, the method of phenomenology involved a concern with essential structures, an attempt to obtain a "pure and unobscured intuition of essences" (Reinach 1968), and even if they consequently claimed that the phenomenological method involved a form of eidetic variation and reduction, where one disregards the hic et nunc of objects in order to focus on their essential features (Scheler 1973, 309), they had little patience with Husserl's insistence on the epoché and transcendental reduction.

The question of whether a proper phenomenological investigation and analysis requires one to perform the epoché and the reduction is, however, not exclusive to philosophy. One can find a similar discussion within applied phenomenology, in particular, within qualitative research. Whereas Jonathan Smith's Interpretative Phenomenological Analysis doesn't appeal to the epoché and the reduction, Max van Manen has insisted that the "basic method of phenomenological analysis consists of the epoché and the reduction" (2017, 820, cf. 2018, 1962), which he then somewhat enigmatically goes on to describe as an opening up (epoché) and a closing down (reduction) $(2017,822)$. The most persistent reference to the epoché and reduction can, however, be found in Amedeo Giorgi, who for many years has insisted that an adaption of the phenomenological method to the human sciences essentially requires that the researcher "brackets or disengage from all past theories or knowledge about the phenomenon" and "withholds existential assent of the phenomenon" (Giorgi 1994, 206). As Giorgi explains, it is essential that the researcher assumes the

attitude of the phenomenological reduction which means that she must resist from positing as existing whatever object or state of affairs is present to her. The researcher still considers what is given to her but she treats it as something that is present to her consciousness and she refrains from saying that it actually is the way it presents itself to her (Giorgi 2012, 4). 
In defending the position that scientific research cannot claim phenomenological status unless it is supported by some use of the reduction (Giorgi 2010, 18), Giorgi does acknowledge the difference between philosophy and science. The kind of phenomenological reduction that should be utilized by psychologists is what Giorgi calls the psychological phenomenological reduction (Giorgi 2012, 5), and not the transcendental-phenomenological reduction, which focuses on consciousness as such rather than on human consciousness.

My focus in what follows will be on these claims, and on the claim that those who seek to practice applied phenomenology, i.e., those who seek to use phenomenological ideas in a non-philosophical context, have to employ the epoché and the reduction if their work is to qualify as phenomenological. ${ }^{1}$

\section{The transcendental-phenomenological reduction}

The suggestion that there is such a thing as a psychological phenomenological (or phenomenological-psychological) reduction might at first seem odd. ${ }^{2}$ Didn't Husserl precisely introduce the epoché and the reduction in an attempt to highlight the distinct philosophical nature of phenomenology and in order to make it clear why phenomenology was precisely not a form of descriptive psychology, despite his own quickly regretted decision to use that label for his project in Logical Investigations? To quickly recap Husserl's line of argument, on his view, a number of fundamental epistemological and metaphysical questions cannot be investigated in a sufficiently radical manner as long as we simply and unproblematically live in the natural attitude. In the natural attitude, we simply take it for granted that the world we encounter in experience exists independently of us. For Husserl, this basic and natural realism cannot simply be presupposed if we want to take philosophy seriously. Rather, it must be critically examined. But, in order to do this, we must first take a step back from our naïve and unexamined immersion in the world and suspend our automatic belief in the mind-independent existence of that world. More specifically, Husserl talks of how the epoché targets and suspends the general thesis (Generalthesis) that belongs essentially to the natural attitude (Husserl 1982, 61). By performing the

\footnotetext{
${ }^{1}$ In assessing these claims, I will have to engage in some detail with the work of Husserl. This is certainly not to suggest that Husserl is the only philosopher qualitative researchers interested in phenomenology should attend to and spend time on, although Giorgi's position could be interpreted as entailing precisely that. To put it differently, researcher who have primarily been attracted to and inspired by the work of Heidegger, Sartre, Merleau-Ponty, or Levinas will undoubtedly have their own issues with Giorgi's claims.

2 A note about terminology is needed. Husserl is not always consistent in his choice of terms. Although he occasionally does speak of a psychological-phenomenological reduction (Husserl 1997, 128, 235), he more frequently calls it the phenomenological-psychological reduction (Husserl 1997, 112, 126), but sometimes also simply speaks of the psychological reduction (Husserl 1977, 179, 1997, 128). Husserl also uses the terms phenomenological reduction and transcendental reduction interchangeably (Husserl 2019, 284), and often speaks of the transcendental-phenomenological reduction (Husserl 1969, 258, 2019, 331). It would be a mistake to suggest—based on the use of these different terms-that Husserl was operating with six different reductions.
} 
epoché, by first bracketing or suspending our tacit belief in the absolute existence of the world, by no longer simply taking reality as the unquestioned point of departure, we start to pay attention to how and as what worldly objects are given to us. But, in doing so, in analysing how and as what any object presents itself to us, we also come to discover the intentional acts and experiential structures in relation to which any appearing object must necessarily be understood. We come to realize that reality is always revealed and examined from some perspective or another, and we thereby also come to appreciate our own subjective accomplishments and contributions and the intentionality that is at play in order for worldly objects to appear in the way they do and with the validity and meaning that they have. When Husserl talks of the transcendental reduction, what he has in mind is precisely the systematic analysis of this correlation between subjectivity and world. This is an analysis that leads from the natural sphere back to (re-ducere) its transcendental foundation (Husserl 1960, 21 ). Both the epoché and the reduction can consequently be seen as elements in a philosophical reflection, the purpose of which is to liberate us from our natural dogmatism and make us aware of our own constitutive accomplishment, make us realize to what extent consciousness, reason, truth, and being are essentially interlinked (Husserl 1982, 340). In this way, we will eventually, according to Husserl, be able to accomplish our main, if not sole, concern as phenomenologists, namely to transform "the universal obviousness of the being of the world-for him [the phenomenologist] the greatest of all enigmas - into something intelligible" (Husserl 1970, 180).

But if this is a correct rendering of the epoché and the reduction, if both are tightly linked to Husserl's transcendental enterprise, and if both are introduced in order to effectuate a general suspension of our natural attitude that will allow for a radical philosophical questioning and for an appreciation of the extent to which objectivity is a constitutive accomplishment, is it then not a significant mistake to suggest that they are equally essential to a non-philosophical application of phenomenology?

When arguing the way he does, Giorgi, however, is explicitly drawing on Husserl's own work. His point of reference is, not surprisingly, primarily Husserl's writings on phenomenological psychology.

\section{Husserl's phenomenological psychology}

In lectures and texts such as Phenomenological Psychology from 1925, the Encyclopaedia Britannica article from 1927, The Amsterdam Lectures from 1928, and The Crisis of European Sciences and Transcendental Phenomenology from 1936, Husserl insisted that his phenomenological analyses could provide a solid eidetic foundation for psychology. This is particularly the case when psychology faces up to the fact that it is a science of consciousness, and not simply-as behaviourists like Watson would claim-“a purely objective experimental branch of natural science," whose "theoretical goal is the prediction and control of behavior" (Watson 1913, 158). In order to develop in a scientifically rigorous manner, psychology needs a proper understanding of experiential life. But this is precisely what phenomenology can offer. Phenomenology returns us to the experiential phenomena themselves, rather than making do with mere speculations and theories about their nature. In 
addition, phenomenology can supply psychology with a fundamental clarification of its basic concepts (attention, intention, perception, content, etc.). More specifically, Husserl argues that the first step of a scientifically rigorous psychology is to obtain detailed descriptions of its own subject matter. But if psychology is to describe the intentional structures of consciousness, it has, as Husserl argues in Crisis, to employ a specific method; it must employ a universal epoché of validity (Geltungsepoché) and effectuate what he calls the phenomenological-psychological reduction (Husserl 1970, 239). In short, in order to thematise intentional consciousness in its essential purity, psychology must employ the psychological epoché and reduction (Husserl 1970, 244). Claims like these are repeated by Husserl in earlier lectures as well. In the Encyclopaedia Britannica article, Husserl speaks of how a pure psychology, a psychology seeking to capture the essence of the mental, must necessarily employ some version of the reduction and the epoché (Husserl 1997, 91). Sometimes, Husserl even speaks of the epoché and reduction in question as involving a bracketing of transcendent positings and argues that one, as a result of enforcing this bracketing, will be in a position to discover the intrinsic intentionality of the mental act, an intentionality that is precisely preserved even if the object doesn't exist (Husserl 1997, 91, 246). Husserl also talks of how the phenomenological psychologist should suspend theoretical prejudices originating from other scientific disciplines in order to focus on what is given, and that its aim is to obtain insights into the essential correlation between act and object (Husserl 1997, 218-219, 223, 230).

Passages like these seem very much to support Giorgi's position. But let us take a somewhat closer look at Husserl's arguments. As we will see, in his texts, Husserl is pursuing two rather different lines of reasoning. On the one hand, when Husserl talks of how psychology needs to employ the epoché and the reduction in order to attain its subject matter, he somewhat surprisingly likens this to the way in which the physicist must also employ an epoché in order to reach her subject matter. Every science needs to bracket extraneous themes if it is to focus on its own distinct topic; every science needs to put out of play those phenomena which are irrelevant for the topic at hand. Just like the physicists must effectuate a universal epoché in order to study the corporeal in abstraction from everything else, so must the psychologist adopt a comparable "abstractive attitude" in order to focus on the psychic domain (Husserl 1970, 230-231, 239).

One can find a similar type of consideration in the Encyclopedia Britannica article, where Husserl observes that the theme of psychology is the psychical being of animal reality. Animal realities are composed of two levels, the first level being that of physical spatio-temporal reality, the second that of mental reality. Animal realities consequently admit of different types of investigation. They admit of a "systematically abstractive" attitude (abstraktive Erfahrungseinstellung) that only focuses on that in them that is purely res extensa. Husserl speaks of this focus as a "reduction to the purely physical." In addition, however, they also allow for a "differently focused abstractive attitude" that allows us to focus on the "psychic in its pure and proper essentialness" (Husserl 1997, 87). To put it differently, just as physical somatology will explore animals and human beings with a systematic methodical focus on only one side of their being, the animate organismic aspect, so pure psychology will explore them with an equally systematic focus on their other side, the purely 
psychic aspect (Husserl 1997, 127). For the psychologist, "the systematic psychological-phenomenological reduction, with its epoché regarding the existing world, is merely a means for reducing the human and animal psyche to its own pure and proper essence" (Husserl 1997, 128).

If one takes these comments literally, the psychological epoché and reduction have next to nothing in common with how the phenomenological epoché and reduction are standardly understood in phenomenological theorizing. The purpose of the latter is not to ignore or exclude anything from consideration. Rather, by suspending or neutralizing a certain dogmatic attitude towards reality, we are precisely supposed better to understand that very attitude and to come to appreciate the processes that enabled it in the first place. It is no coincidence that Husserl occasionally compares the performance of the epoché with the transition from a two-dimensional to a threedimensional life (Husserl 1970, 118). As he writes in Crisis,

What must be shown in particular and above all is that through the epoché a new way of experiencing, of thinking, of theorizing, is opened to the philosopher; here, situated above his own natural being and above the natural world, he loses nothing of their being and their objective truths (Husserl 1970, 152).

It should consequently not come as a surprise that Husserl argues that the psychological-phenomenological reduction and epoché are inauthentic and non-genuine (Husserl 1997, 128). Now, there are fairly obvious additional reasons for Husserl to reach that verdict. Pure psychology, or purely descriptive psychology, or phenomenological psychology (different converging notions) are all positive worldly sciences squarely at home within the natural attitude. Even if the phenomenological psychologist is to effectuate some kind of epoché vis-à-vis the world, even if she is to abstain from any existential positings, the intentional life she is investigating, the psychic phenomena she is describing, remain worldly facts in that they belong to animals and human beings who inhabit a preexisting and taken for granted world (Husserl 1997, 128). To that extent, the phenomenological psychologist is precisely not a philosopher, but a positive scientist who leaves certain fundamental questions unasked. This, of course, is precisely the reason why the psychological-phenomenological epoché and the reduction must be sharply distinguished from their transcendental-phenomenological counterparts.

But this is then where Husserl's second interweaving line of reasoning emerges. On some occasions, he talks of how the psychological reduction is the first preliminary step, and how the transcendental reduction can then be considered a second purifying step (Husserl 1997, 172), one that a radical effectuation of the project of descriptive psychology will by necessity motivate. As he puts it, one might start out with no interest whatsoever in transcendental philosophy, and merely be concerned with establishing a strictly scientific psychology. If this task is pursued in a radical manner, and if the structures of consciousness are investigated with sufficient precision and care, it will eventually be necessary to take the full step, to effectuate a transcendental turn, and thereby reach transcendental phenomenology. At times, Husserl explicitly emphasizes the propaedeutic advantages of approaching transcendental phenomenology in this way, i.e., through phenomenological psychology (Husserl 1997, 174, 251). I will return to this motivation shortly but, for now, it is simply important to understand that 
there might indeed be reasons to view the phenomenological-psychological epoché and reduction as being more in line with the proper and genuine phenomenological epoché and reduction than, say, the epoché and reduction supposedly performed by the physicist or mathematician. But there is a high price to pay for this close affinity. Here is what Husserl writes in Crisis:

Thus we understand that in fact an indissoluble inner alliance obtains between psychology and transcendental philosophy. But from this perspective we can also foresee that there must be a way whereby a concretely executed psychology could lead to a transcendental philosophy (Husserl 1970, 206).

Thus we see with surprise, I think, that in the pure development of the idea of a descriptive psychology, which seeks to bring to expression what is essentially proper to souls, there necessarily occurs a transformation of the phenomenological-psychological epoché and reduction into the transcendental (Husserl 1970, 256).

Ultimately, the phenomenological-psychological epoché and reduction constitute no stable middle ground between naturalistic science and transcendental phenomenology. This is why Husserl eventually argues that there is no such thing as a pure non-transcendental psychology and that it is pointless to treat transcendental phenomenology and psychology separately. In Cartesian Meditations, he writes that psychology insofar as it is the study of consciousness contains a transcendental dimension and is therefore ultimately a part of transcendental philosophy (Husserl 1960, 147). In Crisis, Husserl writes that "pure psychology in itself is identical with transcendental philosophy as the science of transcendental subjectivity" (1970, 258), and that "pure psychology is and can be nothing other than what was sought earlier from the philosophical point of view as absolute grounded philosophy, which can fulfill itself only as phenomenological transcendental philosophy" $(1970,259)$.

So far, both of the argumentative strategies pursued by Husserl leaves it quite questionable whether the epoché and the reduction are really essential to phenomenological psychology. On the first reading, the psychological epoché and reduction have little in common with the phenomenological epoché and reduction except part of the name. On the second reading, they have quite a lot in common, but this very fact ultimately undermines the very independence of phenomenological psychology, which if consistently pursued and developed will necessarily be transformed into transcendental phenomenology. To put it differently, there is something intrinsically self-undermining in the proposal that phenomenological psychology, understood as a distinct qualitative research method different from both naturalistic psychology and transcendental phenomenology, must effectuate steps that if executed correctly will lead to it being absorbed into transcendental phenomenology. 


\section{The transcendental purification}

On a few occasions, however, Husserl himself suggests a way out of this impasse. Towards the end of Crisis, for instance, Husserl writes that the phenomenological psychologist might return to the natural attitude after having performed the transcendental turn, and that she might then practice a transcendentally informed or enriched positive psychology (Husserl 1970, 258). A similar idea can be found in The Amsterdam Lectures, where Husserl argues that one after having first established a firm transcendental foundation can shift back into the natural attitude and then reinterpret everything that has been transcendentally established as psychological structures (Husserl 1997, 248).

In a perceptive article from 1991, Davidson and Cosgrove have highlighted these suggestions from Husserl and sought to develop them further. As they observe, if we follow Husserl, we should recognize that phenomenological psychology is ultimately to be situated within the framework of transcendental philosophy. It has to be established on the basis of a fundamental transcendental clarification, as a radically reformed and fundamentally refashioned discipline that has shed its transcendental naivety (Davidson and Cosgrove 1991, 88). The main difference between itself and transcendental phenomenology proper is simply that the former does not remain in the transcendental domain but returns to the mundane constituted sphere (Davidson and Cosgrove 1991, 88). But how does a psychology which comes after the transcendental reduction differ from one conducted before it? What kind of psychology does it amount to? When spelling out in further details how this transcendentally purified psychology approaches its subject matter, Davidson \& Cosgrove argue that it is interested in the intentional/motivational relation between person and world and that it starts with first-person, subjective accounts of the relevant experiences. In contrast to other approaches, which might share such an interest, but only in order to get a better grip on the explanandum that is then to be causally explained by appeal to various underlying mechanisms, phenomenological psychology proceeds differently. It rejects the naturalistic framework according to which experiences are natural objects brought about by physical causes and instead maintains an exclusive focus on the psychological subject and on his or her life-world experiences (Davidson and Cosgrove 1991, 92). As they write, "Rather than attempting to explain her experience on the basis of underlying causes, we attempt to analyze its meaning and structure from the perspective of the subject as it was lived by her" (Davidson and Cosgrove 1991, 93). For Davidson and Cosgrove, transcendentally purified phenomenological psychology is consequently a psychology which views the meanings and structures of the subject's experiences as arising from her own ongoing constitutive activity, rather than as being mere effects of natural causes. They also argue that the phenomenological psychologist as a result of first having gone through the transcendental reduction is able to leave the "natural attitude" of everyday experience in the life-world behind in favour of the "personal attitude" of the human science (Davidson and Cosgrove 1991, 93).

This later remark should give us pause, however. Do we really need to perform the transcendental reduction in order to be able to gain access to the personal 
attitude? And does the latter really involve a departure from the natural attitude? Both claims reveal a fundamental confusion. The personal (or personalistic) attitude is not opposed to the natural attitude, but to the naturalistic attitude. For Husserl, the latter attitude is a theoretical transformation of the personalistic attitude which is the attitude we normally live in, the attitude of our daily life (Husserl 1989, 240, 252). In short, not only is the personal attitude firmly situated within the natural attitude, but it is also the attitude that is our point of departure, rather than something we need to reach by means of a complicated philosophical procedure. But if phenomenological psychology does not need to be transcendentally purified in order to remain in the personal attitude, does it then at all require the phenomenological epoché and reduction? As we have seen, Davidson \& Cosgrove argue that the phenomenological psychologist must maintain an exclusive focus on the subject's experiences and seek to analyse their meaning from that personal perspective, but again is that not what qualitative researchers are typically seeking to do? Are they not in general considering human experience a topic worthy of its own extensive exploration? Do they not typically strive to take the experiential claims and concerns of the participating subjects seriously? And do they not manage to do that just fine without having to bother with the phenomenological epoché and reduction?

This is precisely what Morley denies in an article from 2010. Morley basically agrees with Davidson \& Cosgrove's analysis and argues that the phenomenological psychologist must first effectuate the transcendental reduction and reach the hyperreflective transcendental attitude before he or she can return to the psychological domain and apply the psychological reduction (Morley 2010, 228-229). But Morley also makes the case that unless the qualitative researcher realizes that objectivity is something that is sustained by us and unless she frees herself from the firm and deep-rooted conviction that the world exists independently of our consciousness of it, she will not be able to maintain her commitment to qualitative research, but will default back into the mainstream naturalistic paradigm with its focus on causal explanations and quantitative measurements (Morley 2010, 223-224).

If this assessment were correct, it would obviously support Giorgi's basic position and approach. But is it really true that you cannot conduct qualitative research unless you have first gone through a transcendental purification, and unless your research is constantly being supported by a transcendental-philosophical framework? I suspect most qualitative researchers would beg to differ and simply continue with their own research without feeling any compulsion to start reading Husserl. And what about those who wish to conduct phenomenological research? Is it reasonable to insist that anybody wishing to conduct applied phenomenological research, anybody wishing to use phenomenology in educational research, experimental psychology, nursing research, sports science, anthropology, sociology, literary studies etc. must first learn to suspend the general thesis and various deep-seated metaphysical assumptions about the mind-independent status of the world and "resist from positing as existing whatever object or state of affairs is present" (Giorgi 2012,4)? If health care professionals wish to use phenomenological ideas in their clinical practice, are they then prohibited from employing notions such as lifeworld, intentionality, empathy, pre-reflective experience, and the lived body in order to understand how different 
dimensions of human existence are affected in pathology, illness, or difficult life-circumstances, unless they first master the theoretical intricacies of the epoche and the reduction? Not only do I think such a claim is without theoretical justification, it has also proven quite counterproductive. Instead of letting qualitative researchers engage with the phenomena themselves, it has led them astray by making them choke on methodological metareflections and generated an enormous amount of publications where protagonists and antagonists alike struggle with these technical and difficult concepts and typically end up misinterpreting both.

For a few examples, consider first the interpretations of Langdridge and Paley. Whereas Langdridge claims that Husserl through his process of bracketing attempted to "transcend [...] the noetic-noematic correlation and take a 'God's eye view' on experience" (Langdridge 2008, 1129), Paley writes that Husserl through the phenomenological reduction tried to "break out of experience (into the realm of pure consciousness)" (Paley 2013, 148). Anybody familiar with Husserl's work will know that both interpretations are misinterpretations. As for a more sympathetic reading, consider van Deursen, who in a paper from 2015 argues that Husserl employed three separate reductions (van Deursen 2015, 60): the phenomenological reduction, the eidetic reduction, and the transcendental reduction. Whereas the first, according to van Deursen, focuses on the noeses and on the processes of consciousness, and the second focuses on the noemata and the objects of consciousness, the focus of the transcendental reduction is on the subject of consciousness and on the nature of the ego (van Deursen 2015, 60-65). Van Deurzen's concern is very much with the use of phenomenology in therapeutic practice and it is possible that this way of discussing the phenomenological procedure might be of value in a therapeutic context. What is quite certain, however, is that van Deurzen's description has no basis in Husserl's writings. Not only does Husserl not distinguish the phenomenological and the transcendental reduction (see note 1 above), but, even more importantly, to suggest that the phenomenological reduction is only focusing on the noeses and not on the noemata; to claim that the transcendental reduction only focuses on the subject and ego, and not on the noeses and noemata; and to insist that the eidetic reduction only aims to uncover the essential and invariant features of the objects of consciousness and not of the acts of consciousness are all claims that fundamentally fail to respect and acknowledge Husserl's correlationism, the fact that the aim of his phenomenological analysis is not to investigate either the object or the subject, either the world or the mind, but to investigate their very intersection, interrelation or correlation (Zahavi 2017).

The reference to the eidetic reduction only complicates matters further. Finlay, for instance, has not only argued that we need to bracket the natural world if we wish to grasp the essential structure of the phenomenon (Finlay 2008, 2, 4), but has also presented the eidetic reduction as the last and final step of the phenomenological method, one that presupposes the prior performance of the transcendental reduction (Finlay 2008, 5, 7). But it is difficult to see why this should be true. The attempt to distinguish essential features from those that are particular, accidental, or incidental is fundamental to most scientific endeavors. The physicist, the chemist, the biologist and the economist are all in different ways trying to obtain fundamental insights, insights that capture essential rather that accidental features of the topic 
under investigation. To assume that they can only do so after they have performed the epoché and the transcendental reduction makes little sense.

\section{The descriptive focus}

At this point, it might be tempting to simply shift argumentative strategy. Perhaps the best argument for why the phenomenological psychologists or anybody else interested in a non-philosophical application of phenomenology should employ the epoche and the reduction are not to be found in Husserl's specific work on phenomenological psychology and in his late claims concerning the ultimate convergence of psychology and transcendental philosophy, but in some of his earlier writings.

According to one interpretation, for instance, it is only by performing the epoché that our own conscious life can become a proper theme of investigation. Our natural and habitual preoccupation is with the non-psychic world. When living in the natural attitude, we are inevitable absorbed by and preoccupied with worldly objects and events, with the what of experience. By performing the epoché, by bracketing our implicit belief in the existence of a mind-independent world, we can finally reorient our attention towards the how of experience, thereby revealing aspects and dimensions of our subjective lives that we normally overlook and ignore (Petitmengin et al. 2018, 2).

According to a different interpretation, the aim of the epoché is to suspend our various theoretical presuppositions. What we have to bracket is our preconceived ideas, our habits of thoughts, our prejudices and theoretical assumptions. By accomplishing that, by jettisoning our theoretical baggage, we can effectuate an unprejudiced turn towards the objects, and arrive at the scene with an open mind, in order to let the objects reveal themselves as what they are (Finlay 2008, 1-2). Finlay also speaks of how the phenomenological attitude (involving the epoché and reduction) amounts to an empathic openness to the world that allows us to engage with the phenomena themselves (Finlay 2008, 29).

Both interpretations are quite widespread, and both can be taken to support the idea that anybody interested in applied phenomenology must employ the epoché and reduction. But both interpretations are wrong. The claim that we need the epoché in order to attend to our inner experiences is mistaken not only by suggesting that the phenomenological attitude should involve such a reorientation towards inner experience, but also in proposing that something like the epoché should be needed for such a reorientation. The claim that we need the epoché in order to bracket any preconceived beliefs, opinions or notions about the phenomenon being researched is likewise mistaken in that it conflates the specific contribution of the epoché (to suspend the general thesis of the natural attitude) with a more general rejection of speculation and explanation in favor of description. But it is wrong to see this preoccupation with description (even the careful description of psychological states) as something that specifically mandates the introduction and use of the phenomenological epoché and reduction. Not only did Brentano already in Psychology from an Empirical Standpoint defend the need for a descriptive psychology and for a careful study of inner experience, but when Husserl in Logical Investigations wrote, "We 
can absolutely not rest content with 'mere words' [...]. Meanings inspired only by remote, confused, inauthentic intuitions_-if by any intuitions at all—are not enough: we must go back to the "things themselves"' (Husserl 2001, I/168), he had not yet introduced the notions of epoché and reduction. And, as already pointed out, many of Husserl's early followers who took inspiration from Husserl's insistence on the importance of attending to things as they are encountered in experience, saw no reason to follow Husserl in his subsequent insistence on the use of the epoché and the reduction. Back in 1914, Reinach, one of Husserl's most talented early followers, gave an influential introductory talk entitled "What is phenomenology?" In the course of his lecture, Reinach explained the nature of the phenomenological attitude, emphasized the importance of getting closer to the thing itself, explained how one might come to learn about experiences one didn't even realize one was having, and stressed the need for a direct intuition of essences. Reinach, however, didn't even mention the epoché and the reduction once in his lecture.

It is well known that Husserl often complained that those of his early followers who failed to follow him in his transcendental turn had ultimately failed to really understand his philosophical project, had failed to fully grasp what phenomenology is all about. I am inclined to think that Husserl was right (Zahavi 2017). I do think that the epoché and the reduction are essential to philosophical phenomenology, and that Reinach to that extent was missing something crucial. I just don't think this also holds true for every non-philosophical application of phenomenology.

At this point, the phenomenological psychologist might be tempted simply to appeal to the authority of Husserl. Husserl did argue that phenomenological psychology requires the effectuation of the epoché and the reduction. Why not simply adhere to his instructions? In addition to the reasons already given for why this would be a bad idea, one should also ask oneself why Husserl started to show this interest in phenomenological psychology. From the context, it should be obvious that he never considered it an end in itself, but rather always as a means to something else, namely philosophical phenomenology. Over the years, Husserl pursued different strategies when it came to introduce the 'unnatural' attitude of phenomenological philosophizing (cf. Kern 1962). One of these strategies was the way over phenomenological psychology. When assessing Husserl's work on the topic, it is consequently important to bear in mind that Husserl was primarily interested in the question of how to facilitate the entry into proper philosophical thinking, and not in providing concrete instructions of how to collect and analyse data or how to conduct interviews or experiments. It consequently seems misguided to primarily base one's methodological framework on Husserl's cursory remarks about how to develop a non-philosophical phenomenology.

\section{Conclusion}

What is then the outcome of these reflections? As should hopefully be apparent, I am not proposing that phenomenology should not be applied, or that qualitative researchers should not seek inspiration in philosophical phenomenology. Phenomenology has over the years provided crucial inputs to a whole range of empirical 
disciplines and helped challenge dominant theories such as psychologism, behaviorism, positivism, and various forms of reductionism. The reason it has been able to do so such successfully is partially because phenomenology is far from merely being a descriptive enterprise. Phenomenology also offers theoretical accounts of its own that can challenge existing models and background assumptions. The fact that phenomenology also has this non-philosophical relevance, the fact that it has served as a powerful source of inspiration for so many disciplines is part of its enduring value. My concern for now has only been with the question of whether those seeking to apply phenomenological ideas in a non-philosophical context need to employ the epoché and the reduction. Is Giorgi right in insisting that scientific research cannot claim phenomenological status unless it is supported by some use of the reduction (Giorgi 2010, 18)? Is Morley right when he in a discussion of phenomenological qualitative research methodology writes, "It's always about the epoché"? (Morley 2010). I obviously disagree. There are other features of philosophical phenomenology that are far more relevant to the qualitative researcher (cf. Gallagher and Zahavi 2012; Zahavi 2018; Zahavi and Martiny 2019).

Let me by way of conclusion make a historical point. If one considers how phenomenology has successfully been applied in disciplines such as psychology, psychiatry, sociology, anthropology etc., over the last 100 years, it is noteworthy how rarely one will find a reference to and a use of the epoché and the reduction, let alone an explicit engagement with Husserl's transcendental project.

Some of the first influential applications of phenomenology were in the domain of psychopathology and experimental psychology. Already in 1912, Jaspers published a short article outlining how psychiatry could profit from Husserlian phenomenology (Jaspers 1912). Some years later, Minkowski reflected on how philosophical phenomenology might be relevant in clinical practice and argued that the use of a phenomenological framework and approach could help the psychiatrist gain a better understanding of the world of the patient. At the same time, however, he also emphasized how philosophical phenomenology might learn from its engagement with psychiatry and psychopathology. Psychopathological investigations, for instance, could lead to a refinement of the phenomenological analyses, insofar as they might point to specific aspects or dimensions of experience that the philosophers had overlooked (Minkowski 1970, xxxix, 6, 171). In the domain of experimental psychology, figures such as Katz not only argued that Husserl's phenomenology was indispensable to psychology (Katz 1950, 18, 1999, 5), but also showed how insights and ideas from phenomenology could lead to better experiments and better theorizing, just as experimental techniques could be used to refine the phenomenological observations and explorations, and make the findings more reliable and intersubjectively accessible. ${ }^{3}$

\footnotetext{
${ }^{3}$ What we already find back then is consequently a vivid example of what subsequently has become known as a relationship of mutual illumination (Varela et al. 1991, 15) or of mutual enlightenment (Gallagher 1997). It was not a question of simply importing and applying readymade ideas from one side to the other; it was not a one-way street from philosophy to psychology, but a two-way exchange, where both sides could profit from the interaction.
} 
What primarily exerted an influence on these and other contemporary figures like Schilder, Straus, and Buytendijk, was, however, often ideas already articulated in Logical Investigations. These included the insistence on the importance of carefully attending to the phenomena in their full concreteness, the importance of unprejudiced descriptions, and the ambition of avoiding what Spiegelberg calls the "premature strait-jacketing of the phenomena by preconceived theories" (Spiegelberg 1972, 308). By contrast, Husserl's insistence on the epoché and the reduction, his explicit defense of transcendental idealism, let alone his lectures on phenomenological psychology did not seem to have had much of an impact-Buytendijk is reported to have said that Husserl's Amsterdam Lectures failed to impress him (Spiegelberg 1972, 282). Spiegelberg ends his impressive survey Phenomenology in Psychology and Psychiatry by arguing that it is urgent to free oneself from some of the technicalities of Husserl's philosophy if a true two-way exchange between psychology and phenomenology is to be possible, and he explicitly warns against "an orthodox return to Husserl" (Spiegelberg 1972, 366). We should ask ourselves which approach has produced the most impressive, innovative and influential results: the heterodox approach of the classical phenomenological psychologists and psychiatrist or the recent and more orthodox approach of Giorgi and colleagues.

Open Access This article is distributed under the terms of the Creative Commons Attribution 4.0 International License (http://creativecommons.org/licenses/by/4.0/), which permits unrestricted use, distribution, and reproduction in any medium, provided you give appropriate credit to the original author(s) and the source, provide a link to the Creative Commons license, and indicate if changes were made.

\section{References}

Davidson, Larry, and Lisa A. Cosgrove. 1991. Psychologism and phenomenological psychology revisited part I: The liberation from naturalism. Journal of Phenomenological Psychology 22(2): 87-108.

Finlay, Linda. 2008. A dance between the reduction and reflexivity: Explicating the "phenomenological psychological attitude”. Journal of Phenomenological Psychology 39: 1-32.

Gallagher, Shaun. 1997. Mutual enlightenment: Recent phenomenology in cognitive science. Journal of Consciousness Studies 4(3): 195-214.

Gallagher, Shaun, and Dan Zahavi. 2012. The phenomenological mind, 2nd ed. London: Routledge.

Giorgi, Amedeo. 1994. A phenomenological perspective on certain qualitative research methods. Journal of Phenomenological Psychology 25(2): 190-220.

Giorgi, Amedeo. 2010. Phenomenology and the practice of science. Existential Analysis 21(1): 3-22.

Giorgi, Amadeo. 2012. The descriptive phenomenological psychological method. Journal of Phenomenological Psychology 43: 3-12.

Husserl, Edmund. 1960. Cartesian meditations: An introduction to phenomenology, trans. D. Cairns. The Hague: Martinus Nijhoff.

Husserl, Edmund. 1969. Formal and transcendental logic, trans. D. Cairns. The Hague: Martinus Nijhoff.

Husserl, Edmund. 1970. The crisis of European sciences and transcendental phenomenology: An introduction to phenomenological philosophy, trans. D. Carr. Evanston, IL: Northwestern University Press.

Husserl, Edmund. 1977. Phenomenological psychology: Lectures, Summer Semester, 1925, trans. J. Scanlon. The Hague: Martinus Nijhoff.

Husserl, Edmund. 1982. Ideas pertaining to a pure phenomenology and to a phenomenological philosophy. First Book. General introduction to a pure phenomenology, transl. F. Kersten. The Hague: Martinus Nijhoff. 
Husserl, Edmund. 1989. Ideas pertaining to a pure phenomenology and to a phenomenological philosophy. Second Book. Studies in the phenomenology of constitution, trans. R. Rojcewicz and A. Schuwer. Dordrecht: Kluwer Academic Publishers.

Husserl, Edmund. 1997. Psychological and transcendental phenomenology and the confrontation with Heidegger (1927-1931), ed. and trans. Th. Sheehan and R.E. Palmer. Dordrecht: Kluwer.

Husserl, Edmund. 2001. Logical investigations I-II, trans. J.N. Findlay. London: Routledge.

Husserl, Edmund. 2019. First philosophy. Lectures 1923/24 and related texts from the manuscripts (1920-1925), trans. S. Luft and T. M. Naberhaus. Dordrecht: Springer.

Jaspers, Karl. 1912. Die phänomenologische Forschungsrichtung in der Psychopathologie. Zeitschrift für die gesamte Neurologie und Psychiatrie 9: 391-408.

Katz, David. 1950. Gestalt psychology, trans. R. Tyson. New York: Ronald Press.

Katz, David. 1999. The world of colour, trans. R.B. MacLeod and C.W. Fox. Abingdon: Routledge.

Kern, Iso. 1962. Die drei Wege zur transzendentalphänomenologischen Reduktion in der Philosophie Edmund Husserls. Tijdskrift voor Filosofie 24: 303-349.

Langdridge, Darren. 2008. Phenomenology and critical social psychology: Directions and debates in theory of research. Social and Personality Psychology Compass 2(3): 1126-1142.

Minkowski, Eugène. 1970. Lived time: Phenomenological and psychopathological studies, trans. N. Metzel. Evanston: Northwestern University Press.

Morley, James. 2010. It's always about the epoché. Les Collectifs du Cirp 1: 223-232.

Paley, John. 2013. 5 questions. In Philosophy of nursing: 5 questions, ed. A. Forss, C. Ceci, and J.S. Drummond, 143-155. Copenhagen: Automatic Press.

Petitmengin, Claire, Anne Remillieux, and Camila Valenzuela-Moguillansky. 2018. Discovering the structures of lived experience: Towards a micro-phenomenological analysis method. Phenomenology and the Cognitive Sciences. https://doi.org/10.1007/s11097-018-9597-4.

Reinach, Adolf. 1968. What is phenomenology? trans. D. Kelly. The Philosophical Forum 1(2): 234-256.

Scheler, Max. 1973. Formalism in ethics and non-formal ethics of values: A new attempt toward a foundation of an ethical personalism, trans. M.S. Frings and R.L. Funk. Evanston, IL: Northwestern University Press.

Spiegelberg, Herbert. 1972. Phenomenology in psychology and psychiatry: A historical introduction. Evanston: Northwestern University Press.

van Deursen, Emma. 2015. Structural existential analysis (SEA): A phenomenological method for therapeutic work. Journal of Contemporary Psychotherapy 45: 59-68.

van Manen, Max. 2017. Phenomenology it its original sense. Qualitative Health Research 27: 810-825.

van Manen, Max. 2018. Rebuttal rejoinder: Present IPA for what it is-Interpretative psychological analysis. Qualitative Health Research 28: 1959-1968.

Varela, Francisco J., Evan Thompson, and Eleonor Rosch. 1991. The embodied mind: Cognitive science and human experience. Cambridge, MA: MIT Press.

Watson, John B. 1913. Psychology as the behaviorist views it. Psychological Review 20: 158-177.

Zahavi, Dan. 2017. Husserl's legacy: Phenomenology, metaphysics, and transcendental philosophy. Oxford: Oxford University Press.

Zahavi, Dan. 2018. Getting it quite wrong: Van Manen and Smith on phenomenology. Qualitative Health Research. https://doi.org/10.1177/1049732318817547.

Zahavi, Dan, and Kristian M.M. Martiny. 2019. Phenomenology in nursing studies: New perspectives. International Journal of Nursing Studies. https://doi.org/10.1016/j.ijnurstu.2019.01.014.

Publisher's Note Springer Nature remains neutral with regard to jurisdictional claims in published maps and institutional affiliations. 